\title{
NÃO SER SÓ UM CARREGADOR DE LIVRO: ELABORAÇÕES DE JOVENS RURAIS SOBRE A ESCOLA
}

\author{
Catarina Malheiros da Silva *
}

\begin{abstract}
RESUMO
Considerando a centralidade da escola para a realização dos projetos individuais, este artigo busca compreender os sentidos das experiências escolares para os/as jovens do Distrito Espraiado e fazendas, localizados em área rural do município baiano de Palmas de Monte Alto. Realizou-se um trabalho de campo, no qual a observação participante, a etnografia e a realização de grupos de discussão constituíram os principais instrumentos de coleta de dados. Foi realizada análise de 02 grupos de discussão com jovens do sexo masculino e feminino, matriculados nos anos finais do ensino fundamental. A análise foi feita com base no Método Documentário de Interpretação desenvolvido por Karl Mannheim e adaptado para a pesquisa social empírica por Ralf Bohnsack. Os resultados apresentados aqui apontam que a escola tem significados positivos para moças e rapazes, haja vista que se trata de uma área rural de pequeno município em que o processo de escolarização se deu de forma tardia e sexista.
\end{abstract}

Palavras-chave: Educação escolar. Conhecimento escolar. Juventude rural.

\section{ABSTRACT}

\section{NOT BEING ONLY A BOOK HOLDER: RURAL YOUNG PEOPLE ELABORATIONS ABOUT SCHOOL}

Given the centrality of school for the realization of individual projects, this article aims to understand the meaning of school experiences for the young people from the Espraiado District and farms, located in the rural area of Palmas de Monte Alto, in Bahia. A field study was conducted in which participant observation, ethnography and discussion groups were the main instruments for data collection. Two discussion groups with young males and females enrolled in the final years of elementary school were implemented.. The analysis was made using the Documentary Method of Interpretation developed by Karl Mannheim as adapted to make it suitable for empirical social research by Ralf Bohnsack. The results presented here indicate that school has positive meanings for girls and boys, given that this is a rural area in a small municipality in which the schooling process took place late and with a sexist connotation.

Keywords: School education. School knowledge. Rural youth

\footnotetext{
* Mestre em Educação. Doutoranda em Educação pela Universidade de Brasília. Pesquisadora do Grupo de Pesquisa GERAJU - Educação e Políticas Públicas: gênero, raça/etnia e juventude. Endereço para contato: Rua Voluntários da Pátria, $\mathrm{n}^{\circ}$ 5, Centro, Palmas de Monte Alto (BA). CEP 46460-000. catems14@yahoo.com.br
} 


\section{Introdução}

Este $\operatorname{artigo}^{1}$ busca compreender os sentidos das experiências escolares para os/as jovens do Distrito Espraiado e fazendas, localizados em área rural do município baiano de Palmas de Monte Alto, já que $a$ atenção exagerada às imagens estereotipadas dos/ das jovens difundidas pela mídia nos impede de reconhecer os sentidos atribuídos por estes sujeitos à escolarização no meio rural brasileiro.

As questões relativas à juventude rural há alguns anos vêm ocupando um espaço importante em minha vida, já que em meu trajeto formativo e profissional os/as jovens do sertão baiano sempre estiveram presentes. Como coordenadora pedagógica no período de 2001 a 2004 nas escolas do ensino fundamental, localizadas em áreas rurais, convivi com jovens estudantes e trabalhadores, que vivenciam experiências nos espaços que frequentam para além da escola. Esse convívio instigou-me a buscar o estudo sobre eles, numa perspectiva que conceba suas vozes como possibilidades expressivas autônomas. É bastante relevante conhecer o significado da escola e do saber escolar para esses jovens, já que, ao observar a dinâmica extraclasse, percebese que o espaço escolar é vivenciado de distintas formas, constituindo-se como local de encontros, para bater papo, namorar, escutar música, ou seja, um espaço de relações sociais. Ir à escola e estar na sala de aula parece não ser a mesma coisa para os/as jovens. Que significados atribuem à escola, considerando a existência dessas vivências?

Na tematização sobre juventude e escola no Brasil, observa-se a escassez de estudos que se proponham a desvelar o sujeito com base na perspectiva da totalidade do ser social e cultural, para além da monolítica dimensão identitária de aluno. Muitos dos sentidos ligados à escola passam hoje pela dimensão da sociabilidade, da convivência entre os jovens e da construção de projetos de vida (SPÓSITO, 2005; DAYRELL, 2005). Historicamente, a instituição escolar pública parte do princípio de que todos os jovens brasileiros provêm de espaços

\footnotetext{
Este artigo apresenta um dos eixos temáticos da pesquisa realizada no âmbito do Programa de Pós-Graduação em Educação/Universidade de Brasília e do Grupo de pesquisa GERAJU, cujo título é: Escola, Saberes e Cotidiano no Meio Rural: um estudo sobre os/as jovens do Sertão da Bahia, sob a orientação da Prof ${ }^{a}$ Dra. Wivian Weller, no período 2007-2008.
}

em que as relações socioculturais, o pertencimento étnico-racial, as relações de gênero e tantas outras dimensões são homogêneos e únicos. Nesse sentido, a desarticulação existente entre o saber mediado na escola e o cotidiano dos jovens que vivem no meio rural reforça a assertiva de que as formas de vida e a cultura dos grupos privilegiados é que são valorizadas e instituídas como cânone.

\section{Juventude e educação escolar no meio rural - algumas reflexões}

No meio rural brasileiro, espaço cada vez mais heterogêneo e diversificado, são tecidas relações socioculturais singulares, ao mesmo tempo em que se mantêm vínculos de dependência com os centros urbanos. Não se pode negar a influência histórica da cidade no campo, cada vez mais acentuada com a urbanização do meio rural e com a absorção de novos elementos políticos, sociais e econômicos em sua prática produtiva e em seu modo de vida. Nesse sentido, "as ruralidades se expressam de formas diferentes em universos culturais, sociais e econômicos heterogêneos" (PEREIRA, 2004, p. 344). O mundo rural pode ser compreendido, então, como lugar de vivências peculiares, em consonância com outras formas de organização social. Por outro lado, pensar o meio rural baseado nas suas singularidades nos possibilita reportar à "invisibilidade" que atinge toda a população rural. Para autores como Veiga (2003) e Abramovay et al (2004), as condições precárias a que são submetidos os sujeitos do campo fortalecem a calcificação de imagens discriminatórias sobre a população rural. $\mathrm{O}$ desconhecimento e negação dos modos de vida dessa população fazem com que as demandas existentes no campo sejam negligenciadas.

A juventude rural figura como parcela dessa população ainda bastante desconhecida, dado o não reconhecimento de problemas específicos que a afeta, ao contrário dos jovens urbanos que são vislumbrados pelas instituições, especialmente no que diz respeito à proposição de políticas públicas. Também não são reconhecidas as práticas de sociabilidade e as vivências culturais, aportadas num contexto específico. Vale ressaltar, no entanto, que essas singularidades estão entrelaçadas com a 
dinâmica da economia e de toda a sociedade. Assim, não se podem instituir fronteiras nítidas entre os universos culturais dos sujeitos do campo e da cidade, já que ambos compartilham projetos que se assemelham (CARNEIRO, 2005).

O entendimento sobre a juventude rural supõe o reconhecimento da existência de espaços distintos a exemplo da casa, da vizinhança e da cidade - nos quais os/as jovens vivenciam cotidianamente experiências individuais e coletivas. Sobre a importância da comunidade local para os jovens rurais, Brandão (1995, p. 136) afirma que "quando há vizinhos por perto, parentes ou não, os grupos de idade alargam os limites da ordem familiar cotidiana e se constituem como os primeiros espaços extrafamiliares de convivência e socialização." Nesses espaços, os jovens constroem relações com amigos, vivenciam o lazer, estabelecem relações com os meios de comunicação de massa, participam de manifestações culturais e religiosas, expressando um sentimento de pertencimento, tanto à comunidade como a grupos de jovens. Nesse sentido, as experiências cotidianas dos jovens dependem da intensidade e da riqueza da vida social existente no meio rural (WANDERLEY, 2006). Daí a relevância da valorização do lugar social da juventude rural, com suas especificidades. Para Vieira (2006), contrariamente à ideia ainda vigente de que só restam no campo os mais velhos, em algumas regiões do país o meio rural concentra uma parcela significativa de jovens homens e mulheres, que constroem distintas trajetórias e formas de pensar e de vivenciar suas condições juvenis.

A compreensão dos significados da escola para os/as jovens do meio rural passa pelo conhecimento dos espaços de vivência e aprendizado extraescolares, numa perspectiva em que o diálogo e o respeito por suas condições de vida passam a ser fundantes. $\mathrm{O}$ ensino público brasileiro ainda não garante aos alunos as condições necessárias para que desenvolvam uma relação significativa com o saber escolar. $\mathrm{O}$ entendimento ainda vigente é o de que o/a jovem, ao rejeitar a escola e o(a) professor(a), não consegue apropriar-se do saber escolar e/ou intelectual.

Segundo Charlot (1996), em muitos contextos educativos, os/as jovens estabelecem uma relação bastante frágil com a escola, pois o que se ensina na escola não faz sentido para o momento presente desses estudantes, mas somente para um futuro distante, que já não pode ser previsto. Conforme destaca Corti (2004, p. 104), "uma das questões centrais hoje, quando se fala na relação dos [as] jovens com a escola, diz respeito à relação dos jovens com o conhecimento. Há, notadamente, uma relação tensa dos jovens com o saber escolar, que precisa ser melhor investigada.” É importante assinalar também que toda relação com o saber escolar é singular e social. Aprender é um processo singular, desenvolvido por um sujeito singular. $\mathrm{Na}$ tentativa de compreender a relação estabelecida entre os jovens e a escola por meio de suas vozes, é importante ainda reconhecer os sentidos atribuídos pelos jovens aos saberes ditos formais ensinados na escola, pois “ “...) se interrogar sobre a transmissão de um saber implica interrogar-se também sobre a postura que a apropriação deste saber supõe, sobre o acesso a certas formas de relação com o mundo, com os outros e consigo mesmo" (CHARLOT, 2001, p. 21).

As relações estabelecidas entre os sujeitos do meio rural e a escola, no momento presente, podem ser compreendidas também com base no entendimento da trajetória da educação rural no passado. Durante muito tempo homens, mulheres, crianças e jovens foram excluídos do acesso à instituição escolar pública. No entanto, embora a educação escolar tenha sido relegada aos homens e mulheres do meio rural, historicamente, observase que os/as jovens rurais têm atualmente maiores chances de continuar os estudos, ao contrário das gerações anteriores (ABRAMOVAY et al, 2004; STROPASOLAS, 2006). Esse cenário possibilita o entendimento do ser jovem no meio rural, uma vez que a ampliação do processo de escolarização favorece o prolongamento da juventude, mediante a existência da dependência e coabitação com a família de origem. Assim, a escola deve conhecer os sujeitos com os quais atua, dentro e fora de seus muros, entendendo a vivência juvenil no meio rural, marcada por um modo de vida singular, como dimensão importante para significar o saber escolar (VIEIRA, 2006).Por fim, é preciso compreender a relação tecida entre os jovens e a escola baseada em uma perspectiva que ultrapasse a sua condição de estudante, concebendo-os como sujeitos que 
estudam e têm outras atividades, que constroem um trajeto escolar e profissional combinado com essas outras dimensões que compõem a vida de cada um.

\section{Itinerários da pesquisa}

O município de Palmas de Monte Alto localizase na Região Sudoeste da Bahia, limitando-se ao norte com Riacho de Santana e Matina, ao sul com Sebastião Laranjeiras, ao leste com Guanambi e ao oeste com Iuiú e Malhada. Dista de Salvador 840 $\mathrm{km}$. Sua população está estimada em 20.779 habitantes, sendo formada por pequenos agricultores, juntando-se a estes, numa relação de complementaridade, comerciantes, funcionários públicos, professores, auxiliares de serviços gerais, profissionais liberais, entre outros. A maioria da população ativa concentra-se no meio rural. Tem como principais produtos agrícolas feijão, algodão, mandioca, sorgo, mamona, milho e arroz. O clima é do tipo quente e seco, apresenta uma temperatura média anual de $22^{\circ} \mathrm{C}$, a precipitação anual é de $700 / 900$ $\mathrm{mm}$ e seu período chuvoso vai de novembro a janeiro. O risco de seca é considerado médio, o que favorece a agricultura de subsistência, inclusive pela sua extensão em área de $2.787,6 \mathrm{~km}^{2}$ (IBGE, 2010). O município é formado pelos distritos rurais de Espraiado, que se localiza a $48 \mathrm{~km}$ da sede; Barra do Riacho, 25 km; Pinga Fogo, 15 km; e Rancho das Mães, distante $13 \mathrm{~km}$.

O critério de escolha do Distrito Espraiado para a realização do estudo está aportado no fato de que a oferta de Educação Básica constitui-se em fenômeno recente nesse distrito, haja vista que as áreas rurais de pequenos municípios brasileiros tiveram um processo de escolarização tardio e sexista. Aspectos como a distância da sede do município, a densidade demográfica e as marcas de isolamento também motivaram a realização do estudo. Espraiado foi reconhecido como distrito em 08 de junho de 2004. Está localizado à margem esquerda do Rio das Rãs, e faz divisa com o município de Riacho de Santana (BA).

O colégio no qual foram localizados os/as jovens é uma instituição de ensino fundamental da rede pública do referido município que funciona nos turnos matutino, vespertino e noturno. O turno matutino é frequentado por crianças oriundas da sede do distrito, que cursam a educação infantil e as séries iniciais do ensino fundamental. Os/as jovens provenientes das fazendas e sede do distrito estudam as séries finais no turno vespertino e chegam à escola no ônibus escolar, que transporta estudantes e pessoas da comunidade. No noturno funciona uma turma de $5^{\mathrm{a}} / 6^{\mathrm{a}}$ série, frequentada por adultos e jovens que estudam na modalidade Educação de Jovens e Adultos (EJA), além de turmas de ensino médio.

Muitos jovens que estudam à tarde e à noite no colégio provêm do Distrito Vesperina, da sede do distrito e de fazendas vizinhas como Alagadiço, Angico, Barrocas, Baldo, Caetano, Caraíbas, Cedro, Covão, Curral Novo, Juá, Jurema, Lagoa do Couro, Malhada Grande, Mari, Muquém, Papaconha, Passagem Funda, Paus Pretos, Pedra de Fogo, Pindoba, Quixaba, Santa Maria, Sertão do Mari, Sítio Canjirana, Tabatinga, Vargem da Cheia. Em algumas destas localidades, existem classes multisseriadas no turno matutino, em prédios escolares construídos na década de 80 do século passado. São 150 alunos(as) que se deslocam das fazendas no transporte escolar rural.

$\mathrm{Na}$ tentativa de reconhecer as especificidades que caracterizam os contextos locais do meio rural, optou-se por realizar uma pesquisa etnográfica na qual a observação participante, as entrevistas com moradores e os grupos de discussão constituíram os principais instrumentos de coleta de dados. Os grupos de discussão foram formados com jovens estudantes do sexo masculino e feminino, tomando-se por base o critério da amizade, ou seja, os próprios jovens determinavam quem participaria do grupo, com a presença de três a seis integrantes por grupo. Foram realizados, no total, dez grupos de discussão com jovens oriundos do distrito e fazendas vizinhas, alunos da $5^{\mathrm{a}}$ a $8^{\mathrm{a}}$ série, na faixa etária de 12 a 18 anos, nos meses de fevereiro e março de 2008. No primeiro momento, optou-se por realizar os grupos com jovens matriculados nos últimos dois anos do ensino fundamental, haja vista que se trata de uma fase em que novas perspectivas e projetos de futuro começam a ser delineados. Questões sobre a continuidade dos estudos, a busca por trabalho 
na cidade, o ingresso em cursos técnicos fazem parte dos interesses desses jovens.

O processo de formação desses grupos ocorreu de forma tranquila e acessível. Como os jovens organizavam-se em rodas de amigos pelo entorno da escola, a abordagem era feita considerando a aproximação existente entre eles(as). Observou-se, ainda, que se organizavam em grupos de rapazes e moças, sendo rara a existência de grupo misto. Os grupos de discussão foram realizados seguindo um tópico-guia que trazia os temas de interesse da pesquisa. A interação entre os membros variou de um grupo para outro. Não obstante serem colegas de sala, em alguns grupos a conversa fluiu; em outros, alguns membros simplesmente mantiveramse em silêncio durante toda a entrevista. Contudo, em quase todos os grupos, assuntos como o fim de semana, família, casamento e eventos escolares foram discutidos com mais entusiasmo. No entanto, na maioria desses grupos a discussão limitou-se aos temas apresentados pela pesquisadora, ainda que ao final da discussão os jovens tivessem sido novamente instigados a falar sobre assuntos que não haviam sido discutidos. Ao término dos grupos de discussão, com o objetivo de obter informações adicionais, cada participante preencheu um questionário com informações relevantes para a constituição do perfil de cada um.

Em seguida, deu-se início à análise dos dados empíricos. Inicialmente, realizou-se a transcrição e divisão temática dos grupos de discussão realizados com os/as jovens. Essa divisão compreende a identificação das passagens/subpassagens e da metáfora de foco. Embora todos trouxessem aspectos importantes para serem analisados, a escolha de grupos representativos para análise era necessária.

Nesse sentido, foi feita a transcrição completa e codificada $^{2}$ de três grupos, tendo-se o cuidado de preservar as marcas de oralidade dos entrevistados, na tentativa de garantir o reconhecimento do dialeto local e da densidade interativa presente nos grupos. Para a análise, foram escolhidos os grupos Os/as jo-

\footnotetext{
2 Os códigos utilizados na transcrição das entrevistas foram desenvolvidos pelos pesquisadores do grupo coordenado por Ralf Bonhsack, na Alemanha (cf. Anexo I). Weller (2005) considera relevante numerar as frases dos membros do grupo, bem como criar códigos para apresentar a entonação da voz e as expressões produzidas pelos participantes. Também assinala a importância de apresentar nomes fictícios para os membros, garantindo assim o anonimato deles.
}

vens que vêm de longe e As meninas que sonham. A escolha está aportada nas especificidades apresentadas pelos referidos grupos, tais como o local de moradia e as representações de gênero. O processo de análise dos grupos foi feito com base no método documentário de interpretação desenvolvido por Karl Mannheim e adaptado para a pesquisa social empírica por Ralf Bohnsack (cl. WELLER, 2005; BOHNSACK; WELLER, 2006).

Considerando os limites deste artigo, serão apresentados a seguir alguns segmentos do eixo escola, dos grupos de discussão Os/as jovens que vêm de longe e As meninas que sonham. No primeiro momento, faz-se uma breve apresentação do perfil dos participantes de cada grupo. Em seguida, a análise do eixo escola que se propõe a entender os sentidos atribuídos pelos(as) jovens à escola, baseado nas elaborações sobre conhecimento escolar, bem como de sua relevância social.

\section{Quem são os/as jovens que vêm de longe}

Moisés (Mm) tem 17 anos, religião católica, negro, $7^{\mathrm{a}}$ série, natural da fazenda Cedro, em Palmas de Monte Alto. Mora nessa fazenda, na companhia dos pais, desde que nasceu. Tem sete irmãos e irmãs. Sua mãe nasceu na fazenda Malhada Grande, é lavradora e ganha $\mathrm{R} \$ 15,00$ por dia. Seu pai nasceu na fazenda Papaconha, é lavrador e ganha $\mathrm{R} \$ 15,00$ por dia. Ambos cursam a Educação de Jovens e Adultos à noite, na fazenda Cedro.

Tatiana (Tf) tem 13 anos, religião católica, negra, $5^{\mathrm{a}}$ série, natural da fazenda Cedro, em Palmas de Monte Alto. Mora com os pais nessa fazenda desde que nasceu. Tem sete irmãos e irmãs. Sua mãe é zeladora e foi a primeira professora da localidade. Tatiana não informou a naturalidade dos pais, a renda, a escolaridade e a ocupação do pai.

Carla (Cf) tem 16 anos, religião católica, negra, $6^{\text {a }}$ série, natural da fazenda Cedro, em Palmas de Monte Alto. Sempre residiu nessa fazenda com os pais. Tem nove irmãos e irmãs. Sua mãe nasceu em Malhada, trabalha em casa e cursa a Educação de Jovens e Adultos à noite, na fazenda Cedro. Seu pai é lavrador e ganha $\mathrm{R} \$ 15,00$ por dia. Carla não informou a escolaridade dos pais e a naturalidade do pai. 
Wesley (Wm) tem 14 anos, religião católica, negro, $7^{\mathrm{a}}$ série, natural da fazenda Cedro, em Palmas de Monte Alto. Reside na fazenda desde que nasceu. Tem quatro irmãos e irmãs. Sua mãe é lavradora e ganha $\mathrm{R} \$ 15,00$ por dia. Seu pai é lavrador e ganha $R \$ 15,00$ por dia. Ambos estão cursando a Educação de Jovens e Adultos à noite, na fazenda Cedro. Wesley não informou a escolaridade e a naturalidade dos pais.

Carlos $(\mathrm{Cm})$ tem 16 anos, religião católica, negro, $6^{\mathrm{a}}$ série, natural da fazenda Cedro, em Palmas de Monte Alto. Mora nessa fazenda, com os pais, desde que nasceu. Tem sete irmãos e irmãs (informa ainda que morreram oito irmãos(ãs)). Sua mãe nasceu em São Paulo, é zeladora e tem o ensino fundamental completo. Seu pai é lavrador. Não informou a renda dos pais, nem a escolaridade e naturalidade do pai (escreveu que não sabe a naturalidade do pai).

João (Jm) tem 18 anos, religião católica, negro, $7^{\mathrm{a}}$ série, natural de Palmas de Monte Alto. Tem domicílio na fazenda Curral Novo desde que nasceu. Tem seis irmãos e irmãs (morreram 2 irmãos(ãs)). Sua mãe nasceu em Candiba (BA), é lavradora e ganha $\mathrm{R} \$ 15,00$ por dia. Seu pai é lavrador e ganha $\mathrm{R} \$ 15,00$ por dia. Informa não saber a escolaridade dos pais e a naturalidade do pai.

\section{0 que os/as jovens que vêm de longe dizem sobre a escola}

Saber o que os/as jovens da fazenda Cedro pensam sobre a escola em que estudam possibilita compreender como vivenciam a condição de jovem estudante, considerando as práticas de sociabilidade, a relação com o conhecimento, bem como os significados que atribuem à educação escolar. Ao serem indagados sobre a escola, descrevem-na como espaço importante, que além de ser divertido e exigente, favorece a aprendizagem de coisas interessantes (Passagem Escola, linhas 4-21):

Y: E vocês poderiam falar um pouquinho assim sobre a escola em que vocês estudam?

Wm: eu gostaria eh que a escola que eu estudo aqui é uma escola muito boa divertida mesmo, muito (2) escola muito perigosa para pegar no pé para nós pra nós poder fazer as coisa mais direito poder saber mais que nós sabe fazer na escola não ser só um carregador de livro e também (2) um discursuzinho melhor ( )

Mm: a minha escola onde eu estudo pra mim é boa porque (1) eu desenvolvi muita coisa aqui nela depois que eu estudei aqui e gosto também dos professores e dos colega

(3)

Cm: bom a escola é importante né porque (1) e eu mesmo e eu tinha saído da escola fiquei umas duas semanas fora da escola ai o Conselho Tutelar foi atrás de mim eu voltei e ainda consegui recuperar ainda (2). Por isso que eu quero é pedir graça a Deus pra mim não sair da escola

Cf: a escola pra mim é importante porque através dela que eu aprendi muitas coisas e hoje também continuo aprendendo

Tf: é a escola pra mim é importante porque depois (1) que eu entrei na escola aprendi muitas coisas interessante

Jm: pra mim também é importante a escola ${ }^{\circ}$ entrei na escola e desenvolvi até bem ${ }^{\circ}$ aprendi uma coisa melhor por isso que eu gosto da escola.

Os/as jovens atribuem um sentido extremamente positivo à escola, dada a sua capacidade de garantir a aprendizagem. No entanto, nesse momento da discussão, não apontam quais aprendizagens obtiveram nessa instituição e os significados concretos destas para a vida cotidiana do grupo. A não explicitação dos conteúdos aprendidos pode estar associada às dificuldades de relacioná-los à sua vida diária, talvez porque o conhecimento escolar mediado não dialogue com as necessidades, interesses e desafios enfrentados por estes jovens.

O reconhecimento social, por ser escolarizado, sobretudo no meio rural - onde os indivíduos sempre foram tratados como ignorantes, iletrados -, aparece como experiência relevante para os/as jovens. A existência da instituição escolar pública no meio rural é recente, o que concorre para a sua valorização como símbolo de desenvolvimento local. O pouco "tempo de escola" de muitos homens e mulheres do campo está inscrito na memória coletiva da comunidade.

Sair da condição de mero "carregador de livro", tal como propõe Wesley, para a de estudante que 
aprende "coisas interessantes" pode constituir-se num desejo de valorizar-se como sujeito "estudado", capaz de produzir um "discursuzinho melhor". A motivação que os/as jovens têm para aprender reforça a esperança de um dia "ser alguma pessoa na vida", ser visto pelos seus iguais como alguém que se apropriou de um capital cultural, que sempre lhes foi negado. Também vigora o desejo de que essa condição favoreça a ascensão social, a mobilidade, aqui traduzida pelo desejo de "um dia ser alguém na vida". Daí a valorização do tempo escolar, que não deve ser desperdiçado.

Talvez por isso o movimento de ir à escola é pensado para além da frequência diária. Embora a viagem cansativa e longa até a instituição favoreça o desânimo, os/as jovens do Cedro vislumbram a possibilidade de permanecer com êxito. Isso implica assumir uma postura frente à escola, tornar-se aluno. A elaboração feita por Wesley confirma o papel da escola na construção do sujeito aluno, sobretudo no que se refere à positivação da cultura escolar. A posição enérgica e disciplinadora da instituição que se propõe a ensinar é apontada pelos jovens como necessária, o que confere responsabilidade ainda maior à escola. A cobrança feita por Wesley à escola, de "pegar no pé pra nós poder fazer as coisa mais direito", apoia-se na expectativa de ter acesso a um ensino de qualidade.

Para esses jovens, a conquista de um "discursuzinho melhor" traduz a busca por um conhecimento a que somente na escola se pode ter acesso, ao mesmo tempo em que ela tem condições de distribuí-lo eficaz e coletivamente. A permanência na escola e, consequentemente, a apropriação da cultura escolar garantem que um tipo de saber específico seja ensinado. Trata-se da inclusão de um saber letrado no cotidiano do mundo rural, por meio dos “estudados” (cf. BRANDÃO, 1999).

\section{Aprender a falar certo}

A relação que os/as jovens estabelecem com a escola é influenciada pelo significado que o conhecimento tem para a vida cotidiana no meio em que estão inseridos. Aprender a língua portuguesa e a matemática é necessário porque as habilidades de leitura, fala, escrita e cálculo são fundamentais para acessar determinados lugares, atividades e, sobretudo, para serem reconhecidos como sujeitos capazes (Passagem Conhecimento escolar, linhas 42-61):

Y: E assim que assuntos vocês acham mais importantes para aprender?

Wm: $O$ assunto que eu acho mais importante assim é (1) o assunto importante é matemática

Mm: Todos os assun- todos os conteúdos pra mim é importante mais importante pra mim é é a conteúdo da língua portuguesa porque ajuda as pessoa aprender a falar mais que não sabe (2) é igualmente a consulta do dicionário mesmo é importante e a matemática (2) e a e a disciplina de inglês também (1) o conteúdo é muito importante por isso que eu a- gosto desses conteúdos

Cm: Pra mim o conteúdo que eu acho mais importante é a língua portuguesa e a e a a matéria de matemática porque a língua portuguesa deixa gente mais né sabendo falar e a e matemática que é importante que às vezes alguém pode ser alguém no futuro pode trabalhar de garçom ai agora a pessoa já pode ao menos saber pas- passar o troco pra outra pessoa

Cf: Pra mim também o mais importante que eu acho conteúdo de língua portuguesa que a nossa língua materna que devemos saber falar porque nem é todas pessoa que sabe falar às vezes sabe falar mas igual algumas pessoas assim da roça sabe falar o português mas não fala correto com medo de errar então não devemos ter medo

Tf: Pra mim a matéria que é mais importante pra mim é todas mas é lin- é (1) matemática e história que fala mais sobre a vida das pessoas

Jm: Matéria pra mim também é boa matéria mais melhor pra mim é a língua portuguesa matemática eu não sei muito muito bem ela (2) mas eu consegue aprender aí um pouco.

A atribuição de significados positivos aos conteúdos escolares pode estar aportada no fato de que estes são concebidos como necessários para que transitem num mundo regido pela circulação de conhecimentos cada vez mais exigentes, que determina as relações sociais. 
O domínio do conhecimento da língua portuguesa e da matemática é concebido como fundamental para a inserção no mundo do trabalho num momento futuro, tal como exemplifica Carlos ao falar da possibilidade de "ser alguém no futuro, (...) trabalhar de garçom”. Como a escola se constitui em ambiente de preparação para o futuro/trabalho, o conhecimento escolar é apontado como relevante, traduzido pela necessidade de "aprender a falar". Estudar significa apropriar-se de saberes que possam melhorar sua condição. A relação que esses jovens estabelecem com o conhecimento é marcada pelas condições sociais de existência.

$\mathrm{O}$ destaque conferido à disciplina língua portuguesa pode estar associado também à forma como as pessoas do meio rural sempre foram referenciadas, sobretudo no que se refere à relação com a linguagem. Conforme a afirmação de Carla, ainda é bastante marcante a ideia de que nesse espaço as pessoas "não fala correto". Nesse sentido, a língua portuguesa é apontada como área do conhecimento que possibilita o aprendizado de uma fala normativa, reconhecida socialmente, tal como propõe Carlos quando diz que "deixa gente mais né sabendo falar". Os/as jovens reconhecem que as pessoas "da roça" expressam-se com dificuldade e atribuem a inibição ao "medo de errar". Fica claro então o quanto a produção oral desses sujeitos é avaliada e julgada nos espaços em que estão inseridos. Diante dessa condição, é à escola que recorrem como instituição que pode qualificálos para romper com essas limitações. Uma fala "correta" é o que demandam esses jovens. A não referência a outros aspectos do ensino da língua portuguesa como importante pode estar relacionada às práticas de ensino ainda vigentes.

A fala constitui-se numa dimensão que os localiza socialmente. "Falar errado", "não saber falar" são estigmas que marcam a trajetória escolar e social de muitos jovens moradores na zona rural, que, ao transitarem nos espaços, sobretudo o urbano, são rotulados pela linguagem, mas também por outros atributos tidos como negativos.

\section{Quem são as meninas que sonham}

Daniela (Df) tem 14 anos, religião católica, branca, $8^{a}$ série, natural da fazenda Angico, em
Palmas de Monte Alto. Mora em Espraiado, há 12 anos, com os pais. Tem cinco irmãos e irmãs. Sua mãe nasceu na fazenda Angico, tem o ensino fundamental incompleto, é gari e ganha $R \$ 70,00$ por mês. Seu pai nasceu em Angico, tem ensino fundamental incompleto, trabalha em associação. Não informou a renda do pai.

Bruna (Bf) tem 14 anos, religião católica, negra, $8^{\mathrm{a}}$ série, natural de Guanambi (BA). Mora na fazenda Muquém, com os pais, desde que nasceu. Tem quatro irmãos e irmãs. Sua mãe nasceu na fazenda Muquém, trabalha em casa e tem o ensino fundamental completo. Seu pai nasceu na fazenda Muquém, é agricultor e tem ensino fundamental completo. Não informou a renda dos pais.

Geane (Gf) tem 12 anos, religião católica, branca, $8^{\mathrm{a}}$ série, natural de Palmas de Monte Alto. Mora com os pais, em Vesperina, desde que nasceu. Tem uma irmã. Sua mãe é professora, tem ensino superior completo e pós-graduação lato sensu. Seu pai é funcionário da limpeza geral e tem o ensino fundamental completo. Não soube informar a naturalidade dos pais. Também não informou a renda de ambos.

\section{O que elas dizem sobre a escola}

Ao propor que falassem sobre a escola em que estudam, buscou-se conhecer os significados atribuídos, as vivências compartilhadas e as expectativas das jovens sobre a escola. A pergunta privilegia o relato espontâneo das jovens, pois são solicitadas a abordar a escola de uma forma mais ampla. A expressão "um pouco", no entanto, pode favorecer a brevidade das falas (Passagem Escola, linhas 4-11):

Y: Vocês poderiam falar um pouco assim sobre a escola de vocês?

Df: Minha escola é boa pois nela eu aprendo coisas assim interessantes que talvez eu posso aprender e ensinar assim pra outra pessoa

(6)

Gf: Na minha escola eu também eu também acho bom porque lá a gente aprende uma fonte de sabedoria gente aprende mais falar que nem ela falou que gente pode ajudar os outros 
Bf: Minha escola eu acho bom porque na escola é onde tá nosso futuro e com escola é que nós somos tudo (5) $\odot 2$ -

O significado positivo da escola está atrelado à possibilidade de aprendizagem que essa instituição assegura. Trata-se de uma aprendizagem considerada relevante, que poderá ser "ensinada" para outras pessoas. A partilha do que foi aprendido na escola parece ser uma ação importante para as jovens, talvez porque vivam num meio em que o conhecimento sistematizado é acessado pelos que frequentam a escola. Essa disposição para ajudar aos que possivelmente não se apropriaram da cultura escolar marca as relações cotidianas estabelecidas entre os que "estudam" e os que não têm "nenhum estudo" no meio rural. A presença de filhos(as) jovens na escola assegura a mobilidade de muitas famílias, que passam a contar com as "ajudas" prestadas pelos "mais estudados" para desempenhar papéis que não prescindem do letramento.

Vale ressaltar, no entanto, que as jovens fazem uma descrição genérica daquilo que aprendem na escola e que poderá ser ensinado. A proposição de Daniela e a complementação de Geane - "aprendo coisas interessantes" - apontam a dificuldade das jovens em fazer elaborações baseadas em exemplos concretos e específicos sobre a escola em que estudam. É importante destacar que essas dificuldades iniciais podem ainda estar apoiadas na forma como a instituição escolar historicamente apresenta-se aos jovens. A avaliação de Bruna - "minha escola eu acho bom porque na escola é onde tá nosso futuro" - parece confirmar o predomínio do tempo futuro como elemento marcante na trajetória escolar das jovens. A experiência de estar na escola é pensada com base no que ela pode ofertar num tempo posterior.

A condição estudantil de muitos(as) jovens na escola está vinculada a exigências que consideram apenas a preparação para o futuro, o que demonstra existir um desconhecimento no que se refere ao cotidiano, aos desejos e inquietações que marcam o momento presente da vida desses sujeitos. Ao postular a garantia de acesso a um futuro promissor, a escola não permite que os/as jovens sejam reconhecidos como possibilidade no tempo presente, momento de ressignificação da vida diária.

\section{Os assuntos mais importantes são aqueles que "fala da juventude"}

Compreender o sentido da escola para os/as jovens implica também conhecer a relação que estabelecem com o conhecimento (CHARLOT, 2001), bem como o significado deste para a sua condição de jovem. Na tentativa de aproximar-se da linguagem empreendida pelas jovens, bem como de conhecer os assuntos e matérias considerados mais importantes, a pesquisadora propõe que falem sobre os assuntos "trabalhados na escola" (Passagem Conhecimento E scolar, linhas 19-27):

Y: E assim quais são os assuntos que vocês acham mais importantes que são trabalhados na escola?

Df: Ah mais=mais importante são todos mas os mais importantes são aqueles que fala assim da da juventude fala assim (2) a ciências mesmo trabalha assim com fala daqueles tipo de doença aids, é todo tipo de doença fala assim que que é que gente não pode assim fi-é ficar assim fa-das doenças fala tudo Aids, é sifilis gonorreia esse assunto eu acho muito importante.

Gf: É importante também que fala sobre a vida nossa é a natureza que está sendo desmatada né

Bf: Eu também gostei muito das ciências porque é um meio de de aprendizagem nossa e um meio de assim (2) é $\odot 2$ - 2 de (3) sabedoria que nós temos assim sobre elementos de como animais florestas pessoas doenças esse tipo de coisa.

Os assuntos apontados como mais importantes são os que "fala da juventude," o que confirma a fala propositiva das jovens sobre um período que vivenciam, a juventude. A fala de Daniela ilustra as preocupações existentes nos espaços educativos, sobretudo na escola, em torno da sexualidade do(a) jovem e das doenças associadas a ela. A disciplina de ciências, e consequentemente a escola, desempenha o papel de falar e orientar sobre assuntos que interessam ao(à) jovem, o que permite rever a ideia amplamente divulgada de que ele/ela não se interessam pela escola e pelo saber.

A possibilidade de adoecer de "aids, sífilis e gonorréia" por não estar informado preocupa Daniela, que parece conceber essas enfermidades como próprias da juventude, dada a disseminação de informações que apontam os/as jovens como 
mais vulneráveis às doenças infectocontagiosas e às drogas. Embora as instituições educativas estejam motivadas para tratar dessas questões, ainda o fazem sem ouvir o que os/as jovens têm a dizer. A abordagem de temas/questões relacionados à condição juvenil no momento presente ainda é feita de maneira verticalizada e dissociada das experiências dos(as) jovens, que não são convidados a falar sobre o que gostariam de aprender na escola. Nesse sentido, as ponderações realizadas pelas jovens moças reiteram a importância do reconhecimento das vozes juvenis rurais como necessárias para redimensionar o modelo de formação escolar mediado pelas instituições públicas.

Para as jovens, os saberes referentes à vida juvenil são necessários para garantir a partilha de experiências coletivas de maneira saudável, participativa e segura, tornando a relação com o conhecimento escolar significativa por estar atrelada às necessidades e desafios que marcam o cotidiano em que estão inseridas.

Ter conhecimento sobre a vida humana, representada na fala complementar de Geane como "a vida nossa," parece reforçar a expectativa de muitos jovens em ver os assuntos, desejos, necessidades inerentes à sua vida sendo discutidos na escola. A referência inicial à disciplina ciências - bem como a seus conteúdos - como o assunto mais importante pode sugerir que temáticas relacionadas à sua condição de jovem ("a vida nossa"), como a sexualidade e a natureza, são as que primeiro aparecem quando são solicitadas a falar do conhecimento.

\section{Considerações finais: análise compara- tiva dos grupos de discussão}

Esta análise busca reconstruir as orientações coletivas dos grupos Os/as jovens que vêm de longe e As meninas que sonham, bem como as interações produzidas pelos(as) jovens sobre a escola, numa tentativa de compreender as divergências, aproximações e singularidades que marcam a relação com esta instituição social, nessa etapa da escolarização. A compreensão dessas questões passa pelo reconhecimento dos aspectos que marcam o processo de escolarização desses jovens, a exemplo da dimensão socioespacial, sexo, raça/etnia, faixa etária e trajetória escolar.
A escola é compreendida também como espaço que tem um valor social relevante no meio rural. Para As meninas que sonham, estar nessa instituição possibilita aprender coisas interessantes que poderão ser partilhadas com os outros. Destacam, assim, o compromisso com os que provavelmente "não têm estudo nenhum", o que acentua as mudanças ocorridas no processo de escolarização do distrito desde a oferta da II etapa do ensino fundamental, em 1992. Se em épocas passadas os "antigos do lugar" passaram por privações e constrangimentos, carregando a alcunha de analfabetos e ignorantes, no momento presente As meninas que sonham estão familiarizadas com a cultura escolar e sentem-se capazes de se movimentar no mundo da cultura letrada. Esse movimento em torno dos significados da instituição escolar para as jovens pode ser observado tomando-se por base a relação estabelecida com o conhecimento escolar. Propagam não apenas a relevância social dessa instituição, mas o seu papel em discutir a sua condição de jovem, no momento presente. As jovens querem que a escola fale sobre esse tempo presente: o de ser jovem. Tempo marcado por dúvidas, medo e insegurança. É importante destacar que, histórica e socialmente, a juventude tem sido referenciada como uma etapa da vida caracterizada pela instabilidade, associando os jovens a determinados "problemas sociais". Eles costumam ser entendidos como deficitários, "problemáticos", não sendo vistos, ouvidos e compreendidos como sujeitos capazes de apresentar questões para além das inseguranças e esperanças dos outros. As jovens parecem saber que estão autorizadas a falar o que a escola precisa abordar, escutar. Clamam pelo respeito por sua condição de vida, o que naturalmente impacta na tradicional predominância do estatuto de estudante.

Já Os/as jovens que vêm de longe apreciam a escola disciplinar, comprometida com o ensino eficiente, que os torne capazes de aprender coisas interessantes e melhorar o discurso. Os jovens acentuam a responsabilidade da escola para com a garantia e eficiência em relação à aquisição de saberes escolares, já que para os/as jovens desse grupo essa instituição está autorizada para esse fim. Propõem que ela os livre do estigma que acompanhou a vida de familiares e conhecidos durante 
toda uma vida: o de "falar errado", "não saber falar" ou "não saber fazer conta". Essa experiência, inscrita na memória de muitos homens e mulheres do meio rural, parece perturbar Os/as jovens que vêm de longe. Talvez por isso seja tão urgente e importante não ser só "um carregador de livro", mas apropriar-se de um "discursuzinho melhor". Entrar no mundo instituído vai além da busca pelo trabalho e pela melhoria de vida; essa entrada está atrelada também ao desejo de ser reconhecido como capaz, como sujeito que se apropriou dos códigos da cultura letrada.

\section{REFERÊNCIAS}

ABRAMOVAY, Ricardo et al. Dilemas e estratégias dos jovens rurais: ficar ou partir. Estudos Sociedade e Agricultura, Rio de Janeiro, v. 12, n. 1, p. 236-271, 2004.

BOHNSACK, Ralf; WELLER, Wivian. O método documentário e sua utilização em grupos de discussão. Educação em Foco, Juiz de Fora, v. 11, n. 2, p.19-38, mar./ago. 2006.

BRANDÃO, Carlos Rodrigues. A partilha da vida. São Paulo: GEIC/Cabral, 1995.

O trabalho de saber. Porto Alegre: Sulina, 1999.

CARNEIRO, Maria José. Juventude rural: projetos e valores. In: ABRAMO, Helena Wendel; BRANCO, Pedro Paulo Martoni (Orgs.). Retrato da juventude brasileira: análise de uma pesquisa nacional. São Paulo: Fundação Perseu Abramo, 2005. p. 243-261.

CASTRO, Elisa Guaraná de; CARNEIRO, Maria José (Orgs.). Juventude rural em perspectiva. Rio de Janeiro: Mauad X, 2007.

CHARLOT, Bernard (Org). Os jovens e o saber: perspectivas mundiais. Porto Alegre: Artmed, 2001. p. 33-50.

Relação com o saber e com a escola entre estudantes de periferia. Caderno de Pesquisa, São Paulo, n. 97, p. 47-63, maio 1996.

CORTI, Ana Paula; SOUZA, Raquel. Diálogos com o mundo juvenil: subsídios para educadores. São Paulo: Ação Educativa, 2004.

DAYRELL, Juarez. A escola “faz" as juventudes?: reflexões em torno da socialização juvenil. Educação e Sociedade, Campinas, v. 28, n. 100, out. 2007. Disponível em: <http://www.cedes.unicamp.br>. Acesso em: 15 mar. 2010.

. A música entra em cena: o rap e o funk na socialização da juventude. Belo Horizonte: UFMG, 2005.

Instituto Brasileiro de Geografia e Estatística (IBGE). Municípios brasileiros. Disponível em: <http://www.ibge. gov.br>. Acesso em: 4 abr. 2011.

NOVAES, Regina; VANNUCHI, Paulo (Orgs.). Juventude e sociedade: trabalho, educação, cultura e participação. São Paulo: Fundação Perseu Abramo, 2004.

PAIS, José Machado. Culturas juvenis. 2 ed. Lisboa: Imprensa Nacional/Casa da Moeda, 2003.

PEREIRA, Jorge Luiz de Goes. Entre campo e cidade: amizade e ruralidade segundo jovens de Nova Friburgo. Estudos Sociedade e Agricultura, v. 12, n. 2, p. 322-351, out. 2004.

SARTI, Cynthia A. A família como espelho: um estudo sobre a moral dos pobres. Campinas: Autores Associados, 1996.

SILVA, Vanda. Sertão de jovens. São Paulo: Cortez, 2004.

SPÓSITO, Marília Pontes. Algumas reflexões e muitas indagações sobre as relações entre juventude e escola no Brasil. In: ABRAMO, Helena Wendel; BRANCO, Pedro Paulo Martoni (Orgs.). Retrato da juventude brasileira: análise de uma pesquisa nacional. São Paulo: Fundação Perseu Abramo, 2005. p. 87-127.

. Transversalidades no estudo sobre jovens no Brasil: educação, ação coletiva e cultural. Educação e Pesquisa, São Paulo, v. 36, n. especial, p. 95-106, 2010.

STROPASOLAS, Valmir Luiz. O mundo rural no horizonte dos jovens. Florianópolis: EDUFSC, 2006. 
VEIGA, José Eli da. Cidades imaginárias: o Brasil é menos urbano do que se calcula. 2 ed. Campinas: Autores Associados, 2003.

VIEIRA, Rosângela Steffen. Tem jovem no campo! tem jovem homem, tem jovem mulher. In: WOORTMANN, Ellen F.; MENACHE, Renata; HEREDIA, Beatriz (Orgs.). Margarida Alves. Brasília: MDA/ IICA, 2006. p. 195214. Coletânea sobre estudos rurais e gênero.

WANDERLEY, Maria de Nazareth Baudel (Coord.). Juventude rural: vida no campo e projetos para o futuro. Recife, 2006. Relatório de pesquisa.

WEISHEIMER, Nilson. Juventudes rurais: mapa de estudos recentes. Brasília: MDA/NEAD, 2005.

WELLER, Wivian. Minha voz é tudo o que eu tenho: manifestações juvenis em Berlin e São Paulo. Belo Horizonte: EDUFMG, 2011.

Grupos de discussão: aportes teóricos e metodológicos. In: ; PFAFF, Nicolle (Orgs.). Metodologias da pesquisa qualitativa em educação: teoria e prática. Petrópolis: Vozes, 2010. p. 54-66.

Grupos de discussão na pesquisa com adolescentes e jovens: aportes teórico-metodológicos e análise de uma experiência com o método. Educação e Pesquisa, São Paulo, v. 32, n. 2, p. 241-260, mai./ago. 2006.

. A contribuição de Karl Mannheim para a pesquisa qualitativa: aspectos teóricos e metodológicos. Sociologias, Porto Alegre, ano 7, n.13, p. 260-300, jan./jun. 2005.

et al. Karl Mannheim e o método documentário de interpretação: uma forma de análise das visões de mundo. Sociedade e Estado, Brasília, v. 17, n. 2, p. 375-396, jul./dez. 2002.

\section{Anexo I - Códigos utilizados na transcrição das entrevistas (modelo criado pelos pesquisadores do grupo coordenado por Ralf Bohnsack, na Alemanha)}

Y: abreviação para entrevistador (quando realizada por mais de um entrevistador, utiliza-se Y1 e Y2)

Am/Bm: abreviação para entrevistado/entrevistada. Utiliza-se " $m$ " para entrevistados do sexo masculino e "f" para pessoas do sexo feminino. Numa discussão de grupo com duas mulheres e dois homens, por exemplo, utiliza-se: Af, $\mathrm{Bf}, \mathrm{Cm}, \mathrm{Dm}$ e dá-se um nome fictício ao grupo. Essa codificação será mantida em todos os levantamentos subsequentes com as mesmas pessoas. Na realização de uma entrevista narrativa-biográfica com um integrante do grupo entrevistado anteriormente, costuma-se utilizar um nome fictício que inicie com a letra que a pessoa recebeu na codificação anterior (por exemplo: $\mathrm{Cm}$, Carlos).

?m ou ?f: utiliza-se quando não houve possibilidade de identificar a pessoa que falou (acontece algumas vezes em discussões de grupo quando mais pessoas falam ao mesmo tempo).

(.) um ponto entre parênteses expressa uma pausa inferior a um segundo.

(2) o número entre parênteses expressa o tempo de duração de uma pausa (em segundos).

$\Gamma$ utilizado para marcar falas iniciadas antes da conclusão da fala de outra pessoa ou que seguiram após uma colocação.

; ponto e vírgula: leve diminuição do tom da voz.

. ponto: forte diminuição do tom da voz.

, vírgula: leve aumento do tom da voz.

exem- palavra foi pronunciada pela metade.

exem:::plo pronúncia da palavra foi esticada ( a quantidade de : equivale o tempo da pronúncia de determinada letra).

assim=assim palavras pronunciadas de forma emendada.

exemplo palavras pronunciadas de forma enfática são sublinhadas. 
${ }^{\circ}$ exemplo ${ }^{\circ}$ palavras ou frases pronunciadas em voz baixa são colocadas entre pequenos círculos.

exemplo palavras ou frases pronunciadas em voz alta são colocadas em negrito.

(example) palavras que não foram compreendidas totalmente são colocadas entre parênteses.

( ) parênteses vazios expressam a omissão de uma palavra ou frase que não foi compreendida (o tamanho do espaço vazio entre parênteses varia de acordo com o tamanho da palavra ou frase).

(-) exemplo :- palavras ou frases entre risos são colocadas entre emoticons.

() (2) () número entre sinais de emoticon expressa a duração de risos assim como a interrupção da fala.

((bocejo)) expressões não-verbais ou comentários sobre acontecimentos externos, por exemplo: ((pessoa acende cigarro)), ((pessoa entra na sala e a entrevista é brevemente interrompida)) ((risos)).

//hm// utilizado apenas na transcrição de entrevistas narrativas-biográficas para ou // () (1) ๑// indicar sinais de feedback ("ah," “oh," "mhm") ou risos do entrevistador.

Recebido em 02.05.2011

Aprovado em 22.08.2011 